\title{
La columna infame de Milán en tiempos de pandemia
}

\author{
Milan's infamous column in times of pandemic
}

Esteban Rodiguez ${ }^{\mathrm{a}, \mathrm{b}}$

\begin{abstract}
Resumen
Las épocas de pandemia han despertado y despiertan miedo en individuos y pánico en sus comunidades. En este artículo el autor repasa brevemente los hechos históricos ocurridos durante La Gran Plaga (pandemia de peste bubónica) que dieron lugar a la denominada Columna Infame de Milán, haciendo un paralelismo con algunas situaciones de criminalización de los enfermos e individuos afectados por la actual pandemia de SARS-Cov-2.
\end{abstract}

Palabras clave: Historia de la Medicina, Enfermedades Transmisibles, Infecciones por Coronavirus. Keywords: History of Medicine, Communicable Diseases, Coronavirus Infections.

Rodriguez E. La columna infame de Milán en tiempos de pandemia. Evid Actual Pract Ambul. 2020;23(3):e002089.

"Los errores y los males del pasado no son nunca pasado, es preciso vivirlos y juzgarlos de continuo en el presente"

\section{Leonardo Sciascia}

Durante una de las tantas pandemias de la historia de la humanidad, los habitantes de Milán en la Región de Lombardia de Italia nos dejaron sin saber, una enseñanza muy útil en estos tiempos. La Peste Bubónica -una enfermedad bacteriana que todavía existe en la actualidad- provocó muchos brotes en distintos lugares del mundo pero se destacaron tres pandemias: La Peste de Justiniano, La Peste Negra y La Gran Plaga. Simplificando las cosas la primera provocó la caída del Imperio Romano de Oriente; la segunda aceleró el paso de la Edad Media a la Edad Moderna y la tercera es la que recordaremos brevemente en este tiempo de COVID ${ }^{1}$

Los hechos en forma breve serían algo así: por el 1630 Milán estaba siendo asolada por la peste bubónica en forma inusual lo que generaba miedo individual y pánico colectivo. Al no estar claro cómo se propagaba esta enfermedad se buscaban chivos expiatorios para intentar frenar el descontento del pueblo, perjudicando sin razón a veces a algún individuo perteneciente a alguna minoría -extranjeros, leprosos o judíos-, o bien, a vecinos comunes. Muchas personas fueron linchadas por motivos triviales o por algún gesto que parecía inusual como el de un pobre anciano que vieron en la iglesia limpiando el banco con un paño antes de sentarse. Es que ya se había difundido la creencia de que determinadas personas untaban murallas y portones con una sustancia que era la causante de esta enfermedad. De esta forma se llegó a la denuncia de una anciana que acusó sin pruebas a otras dos personas por untar las paredes de la zona con esa supuesta sustancia pestífera y venenosa; esas dos personas (Piazza, un comisario de salud pública y Mora, un barbero) fueron llevadas a juicio, torturados para obtener una confesión -a cambio de falsas promesas de impunidad- sobre algo que no hicieron y luego sentenciadas a una muerte terrible en el patíbulo: previas quemaduras con hierros calientes en distintas partes del cuerpo, se les cortó la mano derecha con la que supuestamente habían untado esas sustancias, les quebraron todos los huesos a golpes y los dejaron allí por seis horas de largo suplicio para luego matarlos y quemarlos, lanzando sus cenizas al río (ver Figura 1). La casa del barbero fue arrasada y se construyó allí una inmensa columna para recordar el crimen y la pena de estos supuestos untadores infames, que pasó a llamarse la Colonna Infame (ver
Figura 2). Con el tiempo se pudo comprobar que no era cierta aquella denuncia, pero el daño ya estaba hecho y lo infame no fue lo que (no) hicieron esos dos vecinos sino las estupideces que cometieron los milaneses que habían apoyado todos los eventos y las atrocidades del juicio. Si bien algunos dicen que hay restos de la columna en un museo del Castillo Sforza en Milán, la realidad es que en 1778 ésta se mandó a derrumbar y se construyó allí una casa, debido a que el monumento había pasado a ser algo vergonzoso para los habitantes de esa ciudad ${ }^{2}$.

Figura 1. La sentenza data a Guglielmo Piazza e Gio. Giacomo Mora quali con onto pestifero hanno appestato la città di Milano l'anno 1630. Autor desconocido. Fuente: https://commons.wikimedia.org/wiki/File:La_sentenza_data_a _Guglielmo_Piazza_e_Gio_Giacomo_Mora.djvu

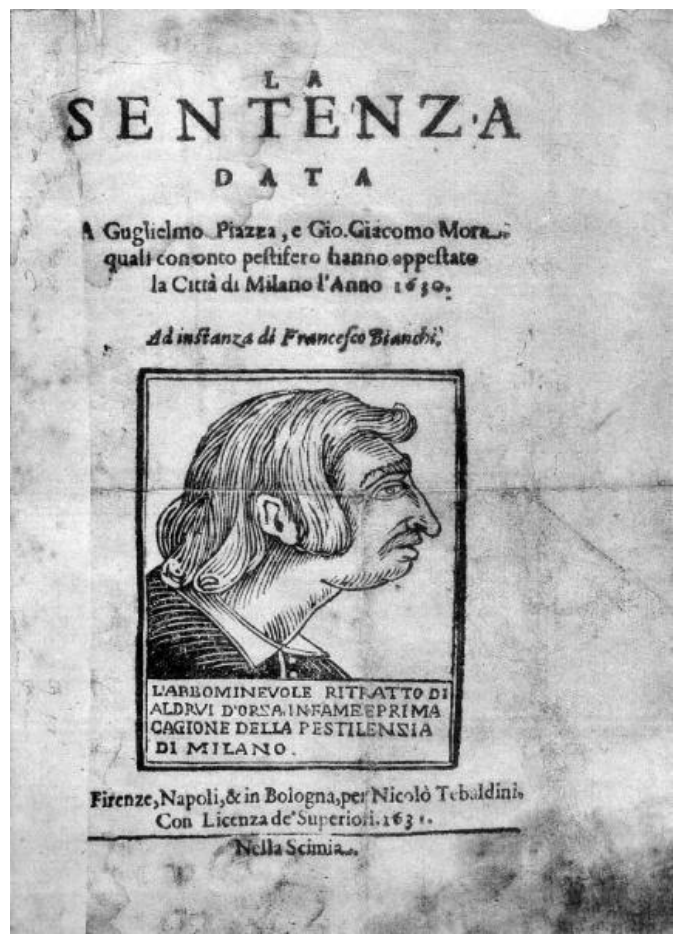

En nada se parecen como enfermedad la Peste Bubónica y el COVID, pero generan los mismos miedos y reacciones y la colum-

\footnotetext{
a Hospital Italiano Monte Buey.

b Posse Salud. medicinadeldxt@hotmail.com
} 
na infame milanesa debe hacernos recordar lo que no hay que hacer como pueblo.

Hay muchos Piazza y muchos Mora que simplemente haciendo sus trabajos son señalados, acusados y hasta juzgados. Afortunadamente esto ya no sucede en un patíbulo, pero sí en las redes sociales (¿sociales?). Luego de uno o muchos clicks, estas se han transformado en un calvario para muchas personas que nunca fueron criminales.

Sin dudas tenemos que cuidarnos de las pandemias pero también de las personas que propagan noticias falsas 0 indebidas que hacen mucho daño, incluso más daño que el propio microbio. Hace mucho fue la peste, ayer fue la lepra, la tuberculosis o el
SIDA y hoy el COVID. ¿Y mañana cómo se llamará?

Siempre la humanidad ha terminado pudiendo prevalecer frente a las más terribles pandemias de la historia. ¿Pero, podremos prevalecer ante nuestros semejantes? ¿O el hombre será lobo del hombre?

Si los milaneses pudieron derribar la columna infame nosotros podemos como sociedad demoler algunas actitudes para construir otras útiles, porque en definitiva las grandes crisis son también grandes oportunidades.

No debemos permitir que la Columna Infame de Milán siga en pie en cada uno de nosotros.

Figura 2. La sentenza data a qvelli che hanno avelenato molte persone in Milano l'an 1630. Fuente: Biblioteca Nacional de Medicina de los EE.UU. http://resource.nlm.nih.gov/101392772

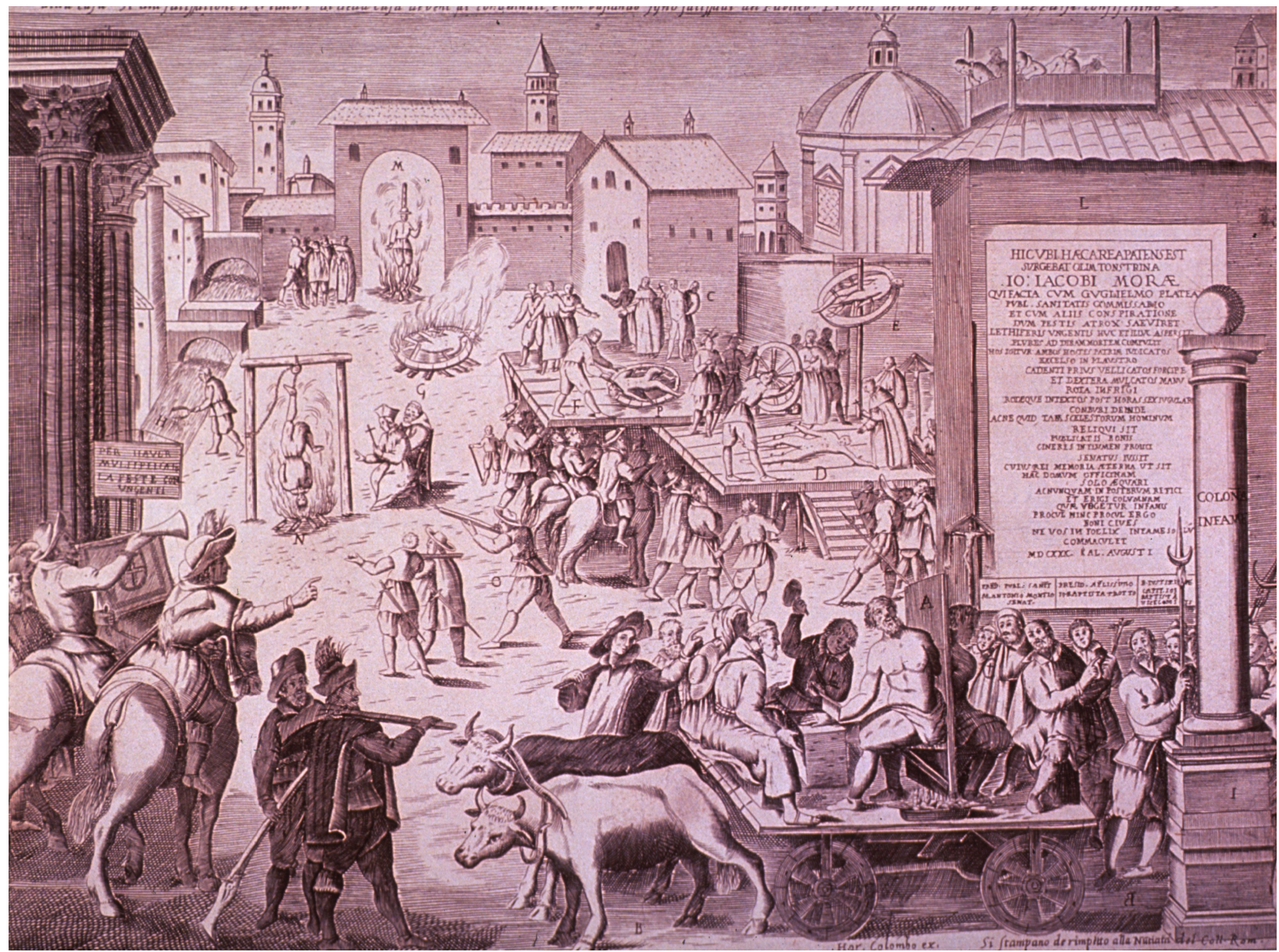

\section{Agradecimientos}

A la Biblioteca Central del Instituto Universitario Hospital Italiano de Buenos Aires, especialmente a Virginia Garrote, por las imágenes que acompañan este artículo.

\section{Referencias}

1. Madera PG. Breve historia de la medicina. Madrid: Nowtilus; 2011.

2. Manzoni A. Historia de la columna infame. Madrid: Alianza; 1987. 